\title{
The Relationship Learning and Knowledge Based View of Strategy
}

\author{
Bassam Abu Khudair \\ Al-Huson University, College, Al-Balqa' Applied University, Al-Huson, Jordan \\ Email: khdairbassam@yahoo.com
}

How to cite this paper: Khudair, B.A. (2018) The Relationship Learning and Knowledge Based View of Strategy. Open Journal of Business and Management, 6, 333-348.

https://doi.org/10.4236/ojbm.2018.62024

Received: February 21, 2018

Accepted: April 22, 2018

Published: April 25, 2018

Copyright $\odot 2018$ by author and Scientific Research Publishing Inc. This work is licensed under the Creative Commons Attribution International License (CC BY 4.0).

http://creativecommons.org/licenses/by/4.0/

\begin{abstract}
The rate of learning is determined by the method that one comes up with the information. The identical substance can be realized often times quicker if properly formulated. This work aims at fostering multidisciplinary dialogue and study about knowledge-intensive methods to learning administration as well as studying procedures in the person, business and countrywide amounts, focusing information portrayal problems, sociable and organizational components, architectural, and layout concerns associated with studying supervision systems. Moreover, business strategy can be defined as set of plans in order to achieve the required goals. While nowadays, there is no accurate definition of strategy. In this work, collection of strategy definitions, research methods, industrial economics view of strategy, resources based view of strategy and the competitive dynamics view of strategy are explained in details. Moreover, the related research including strategy definitions is previewed.
\end{abstract}

\section{Keywords}

Knowledge, Different Kinds of Knowledge, Resource Based Perspective View, Knowledge Based Perspective View, Strategy, View of Strategy

\section{Introduction}

The actual outdoors framework is seen becoming a group of intangible associations along with customers in addition to vendors, which may out of your reason behind reputation picture in the real firm. Some of these connections may become authorized residence for instance photos in addition to brand names [1]. The need for these kinds of intangible sources is totally primarily counting on just how correctly the business endeavor relates to its consumers' difficulties, concerning much uncertainness. Reputations along with associations may be negative or perhaps good, and can alter over time [2].

The household regarding inside framework sometimes appears to keep patents, 
ideas, variations, internet web templates, employee's personnel computer (PCs) and other administrations pretty much specific procedures [3].

The particular casual strength enjoys this internal Internet sites and the particular traditions, or maybe the spirit can be viewed to get along with within construction. It is useful to include the specific effectiveness of people in the within system, as well as administration inside of construction household, because the inside platform is out of your suppliers [4].

Inner structure is set up most reliable people to abandon a business that will depend substantially on them, just like a becoming any kind of advisory company, at least portion of the inside and the exterior properties will probably remain undamaged and might act as this system [5].

Consist of this effectiveness from the specialist employees, experts, the particular study as well as advancement (R\&D) people, the particular maker workers, advertising and marketing-the bottom line is almost all people with a good instant connection [6]. The particular superiority among specialist staffs in addition to dealing with personnel is going to make her different features figuring out in the same way which they link together and the way these individuals interact with the specific outside earth [7].

This type of Staff is well suited for method along with activities organizing. Among professional specialists along with management employees are typically inside knowledge-intensive organizations, which are good for instance discussion in the principle due to the fact deficiencies in details talking about concerning several individuals [8].

\subsection{Learning and Knowledge}

Studying just like a sensation presents always intrigued individuals in several disciplines, and also there are numerous tips and also view regarding precisely what Studying will be. It is possible to transfer Dating back to find out tips of understanding and info. Your hypotheses within these kinds of sources are normal inside the 20th century [9]. This TIP-database offers an extremely considerable examine learning hypotheses. Each and every personal notion typically concentrates on an incredibly certain thought, get older as well as topic to learn, and are also not really frequent. One problem, and also a fantastic problem is the fact there's no principle associated with knowing that is actually generally acknowledged [10]. This isn't unbelievable when we monitor from studying and find out precisely how considerable this pattern is actually. Learning is often a complex feeling which includes several factors. Age group, sex, way of life, topic and type of information are often forms of parameters in which get a new studying the strategies, end result, and so on [11]. The purpose with this perform should be to examine the specific tips associated with learning and data to be able to kind any theoretical reason for more aid creating entertaining understanding environment aimed to satisfy the long run. To offer a whole review and even report on learning ideas is in fact at night range of the study, and also the 
objective from the region is just to give a review of a couple of crucial practices also to highlight a few concepts which is often significant pertaining to layout related to computer which usually help knowing depending on understanding as demonstrated in Figure 1 \& Figure 2.

\subsection{Different Kinds of Knowledge}

Most of individuals agree regarding understanding that it is the complex facet of the complexity in its wide selection. Nevertheless, there is certainly whole lot

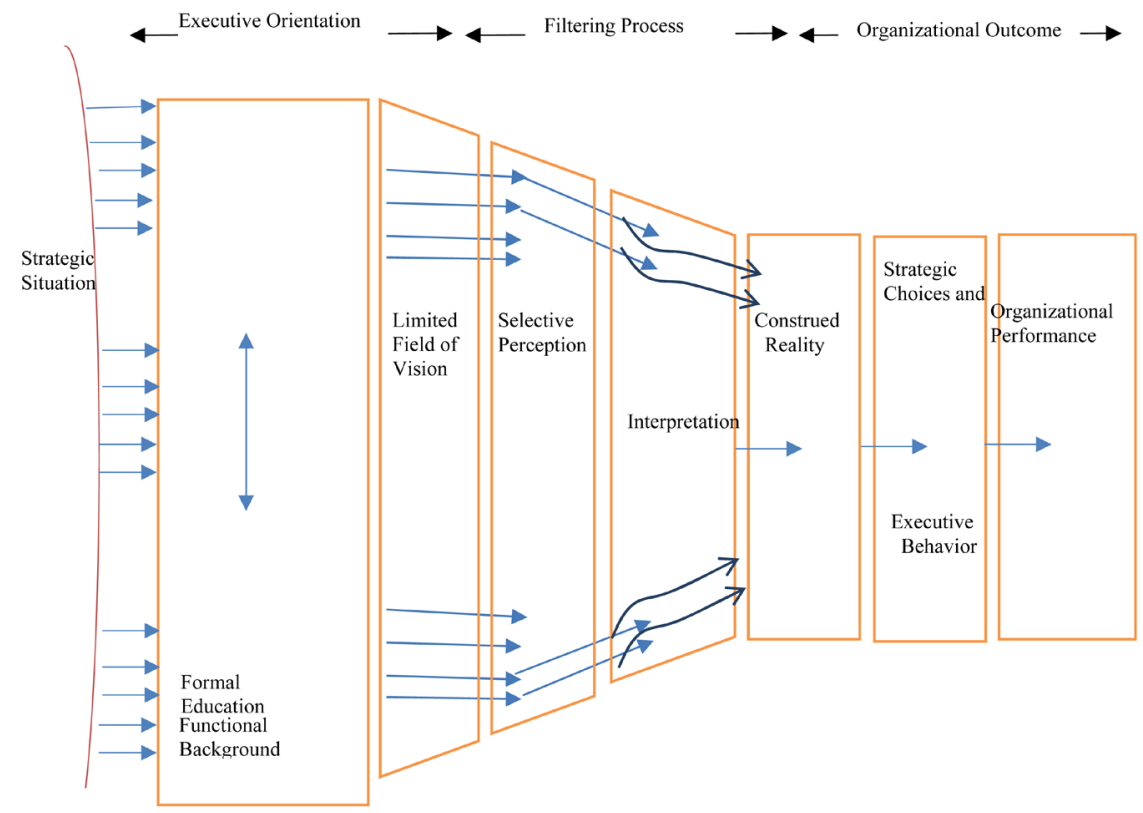

Figure 1. Cognitive learning theory.

Cognitive Learning Theory

Psychological Factors

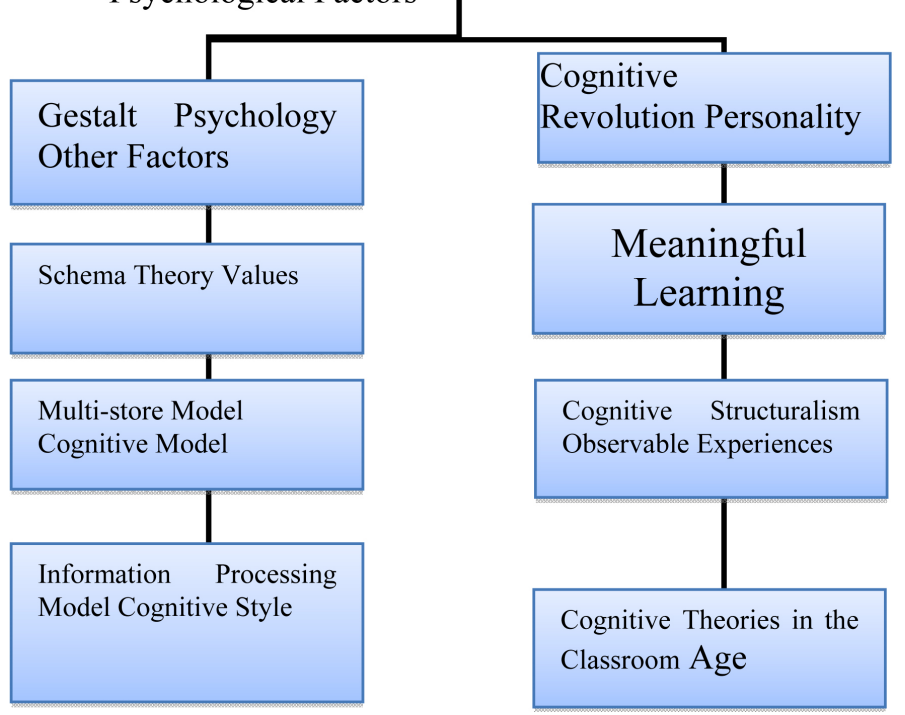

Figure 2. Cognitive learning. 
turmoil more than just exactly what are, exactly, the several types of info a decided grasp checklist basically not can be found. For the reason that understanding is actually solely philosophical; arguments period centuries, justifications supersede actuality and everyone includes a different viewpoint about what is in fact, or is not really, knowing. Beneath is really an understand checklist although, of course, this will not necessarily become organized of the several types of knowing and practices of data which can be available on the market. Flip this particular new-found information upon your self-using this great course regarding how to consider supply relating to yourself and acquire authentic self-knowledge [12] [13]. Where, the different kinds of knowledge are divided into six items as:

1) Priori

2) Posterior

3) Explicit Knowledge

4) Tactic Knowledge

5) Propositional Knowledge

6) Non-Propositional Knowledge

Explaining each item in details as below:

\subsubsection{Priori}

Any priori and a few rears are a couple of the original circumstances inside epistemology study regarding knowledge. Virtually any prior-literally suggests from prior to or even by means of earlier. This can have to be priori comprehending is determined by just what an individual can outcome around the globe and not having to sense that. This can be higher quality simply because considering. Concerning program, a diploma of experience is important from then on virtually any prior knowledge may take situation [14].

Let us discover an example. Had you been in the sealed location without having Home windows as well as an individual asked an individual what the weather was such as, you would struggle to reaction all of them with anywhere regarding reality. In the event you perform, then you definitely could not survive inside ownership of the prior knowledge. It could you should be extremely hard to work with considering to create a well-informed reaction [15].

\subsubsection{Posterior}

Very easily, next, posterior-literally implies coming from just what should come. Soon after or perhaps through what uses. This is sometimes a mention of the expertise and also using an alternate kind of considered inductive to obtain knowing. This sort of information will be acquired beginning with having a good expertise and also the essential thought inside of viewpoint is it is in fact obtained with all a number of feelings after which using common sense and portrayal in order to acquire comprehension from this. Within viewpoint, this type of expression may also be utilized interchangeably with analyze information, which can be info according to declaration [14]. 
It is believed that any priori comprehending is more dependable when compared to a posteriori knowledge. This may appear counter-intuitive, due to the fact in the past situation someone can certainly simply sit inside a space along with base their particular information on informative info inside last option situation somebody is having real runs into in the world. The main problem is within this particular very reality: everybody runs into are usually very subjective as well as ready to accept decryption [15].

\subsubsection{Explicit Knowledge}

Very revealing information is exactly the same with a priori information within that it is much more conventional or more dependable. Specific details will understand which is recorded in addition to presented by way of platforms. It's our local library and also sources. The specific more information about what exactly is included is truly a smaller sized quantity vital as compared to how it is covered. Something in the sciences for the Arts may have components which may be suggested inside of really exposing knowing. The particular identifying feature regarding specific details are it could be merely along with rapidly transported in one private to a new, so that you can another ten-thousand or ten-billion. Furthermore, It is commonly organized carefully [16].

\subsubsection{Tacit Knowledge}

Although certain information is very simple to speak as well as exchange from individual to a different, tacit comprehending is strictly the alternative. It is rather tough, as well as hard, to speak tacit information via virtually any moderate. As an example, the particular textbook around the founding regarding, however somebody that is skilled music performer can't genuinely communicate his or her information; quite simply, they cannot inform somebody the best way to perform within the gadget as well as the person may instantly have got that information. Which details must be purchased having a degree that goes significantly, on this perception, tacit knowing might numerous very carefully seem like a posteriori knowledge, as it could certainly just be accomplished by means of experience. The largest hard related to tacit information understands when it is helpful and also foreseeing apart how you can make sure it is functional. Tacit details could only be presented by way of regular as well as extensive associations or even make contact with which includes making use of instruction from your specialist music artist. But even just in these particular circumstances there will never be a genuine move of data. Generally, 2 kinds of understanding are usually created, due to the fact every person has to fill in certain greeting card greeting card blanks [17].

\subsubsection{Propositional Knowledge}

Propositional information has the oddest Classification however, since it is generally kept its info that may virtually be pictured inside propositions; that is, in declarative articles to Make Use of Its extra determined or possibly a sign propositions. Propositional knowledge is not thus diverse from your priori and specific 
comprehending. The main element feature knows that thing is valid. Yet again, Statistical equations might be an example of propositional knowledge, because it understands of something, rather than more knowledge about ways to do something (David et al., 2012). The very best example is but one in which contrasts propositional details with our future form of information, non-propositional or maybe Step-by-step knowledge. Let's utilize a textbook pamphlet including here is how to be able to program your personal computer since the illustration. Propositional understanding just understands one thing or even acquiring understanding of one thing, when you examine and/or committed to memory the book or perhaps Handbook, then you would know the activities regarding how to strategy some sort of personal computer. You may also copy these kinds of steps so that you can somebody else because declarative sentences or possibly a signal propositions. However, you might have memorized each word however do not know the best way to really plan a PC. That is where non-propositional and even Step-by-step information.

\subsubsection{Non-Propositional Knowledge}

Step-by-step details are distinctive from propositional information inside that it's obtained through undertaking; propositional knowing is in fact received simply by more common kinds of studying. One of the determining characteristics regarding Step-by-step knowing is it could be produced in any court of law. Basically, organizations which usually produce their own treatments or even methods can look after these because intellectual home. Step-by-step information provides several advantages. Clearly, hands-on encounter is very helpful; really therefore, as they can be familiar with acquire work. We have been looking at this sort of these days because experience Step-by-step is going to be eclipsing training propositional [18]. Positive, training is fantastic, however encounters exactly what specifies exactly what a person is able to accomplishing. So someone who is able to write Program code seriously isn't nearly because beneficial as someone who creates or perhaps has created Sign. However, many people feel that this is sometimes a double-edged edge, due to the fact the quantity of experience essential to grow to be adept limits all of us for some relatively slender business of selection [19].

Yet No one can certainly refuse the inborn and genuine price of experience. This kind of is a lot more correct as compared to propositional info simply because it's much more similar to this medical approach; ideas are examined, assertion can be used, along with improvement final results.

\subsection{What Is Strategy?}

The thought of process has bought increasing concentration within the administration literature. The literature on approach is now voluminous and strategic management texts develop ever greater to include all of the significant material. In this work, the goal is to not quilt the entire field of strategy that might require yet one other substantial tome however to present a transparent, logical and suc- 
cinct process to the field in order to be of use to the working towards supervisor [20].

The premise is that a company needs a good-defined feel of its mission, its certain place in its environment and scope and direction of progress. One of these experience of mission defines the corporation's method. An organization additionally wants a strategy to management itself in an effort to harness the interior energies of the organization to the cognizance of its mission. Historically, views of process fall into two camps [21].

There are folks that equate procedure with planning. In keeping with this viewpoint, know-how is gathered, sifted and analyzed, forecasts are made, and senior managers mirror upon the work of the planning division and come to a decision what's the satisfactory direction for the group. This can be a prime-down technique to technique [22].

Others have a less structured view of process as being more concerning the process of administration. Consistent with this 2nd standpoint, the important thing strategic predicament is to place in location a method of administration on the way to facilitate the capability of the institution to respond to an environment that is practically unknowable, unpredictable and, for that reason, no longer amenable to a planning technique. On account that both these views on this text. The own view is that excellent strategic management definitely encompasses factors of each viewpoint [23].

There is no one great means of strategy. The planning technique can work in a stable, predictable atmosphere. Its critics argue that such environments are fitting more and scarcer, events make the plan redundant, and creativity is buried underneath the load and protocols of planning and verbal exchange ideas [24]. In addition, those now not concerned in devising the plan are by no means committed to its implementation. The second strategy emphasizes pace of response and flexibility to enable the organization to function exceptional in an atmosphere that's quick-altering and pretty much unpredictable. The essence of strategy, in line with this view, is adaptability and instrumentalism. This approach has been criticized for failing to offer a sufficient feel of the place the institution goes and what its mission.

\section{Competitive Dynamics}

In real life, all companies must compete with each other's, otherwise if in their plan to win, this means that they are required to gain the strategic competition in the new period of the competitors. Moreover, being away from competitive business and coming into view for the third world international is by itself a squeezing process, this is called an approach and sometimes called dynamic. This process gives the leaders of the companies to recalculate and redesign their plans and reevaluate their visions and do strength, weaknesses, opportunities threat (SWOT) analysis as shown in Figure 3.

Strategic actions are arranged in order to support and enforce the institution's 
industry-stage technique and symbolize enormous commitments of designated and exotic resources and are complex to put into effect and to reverse [25]. Moreover, tactically process refines the strategy, also can be considered as easier method for the competitors in order to be faster in their replies, this can be characterized by taking of the financial risks in the hope of profits in the industries which are characterized by:

1) Important item which is the speed, but the oncoming to the principal is stringent.

2) Fighting with markets to establish a sanctuary or a shape of market ascendancy.

3) Stronger competitive opposition is helpful for client's allegiance.

4) Production's quality is profitable with the suppliers in order to set up a prospective advantage.

5) Companies endeavor in order to build their characters.

6) The diversity of the competitive strategies, also reducing the direct competition and enabling the sanctuary ascendancy.

\section{Decision Making Strategy}

In the earlier decade, the research for the decision making was wealthier, as much as enchanting for reading. Moreover, improvement in decision making as it's known did not match its practice. Making decision can be defined as the processes which identify the right selection by collecting a lot of alternatives in order to get a unique predilection. Also getting many decisions in order to obtain a successful plan in the career of any company, this happens by collecting more than one goal and deciding how to reach them successfully [26].

The fact is that folks must make up their minds in an exceptional type of instances, and it's a source of bewilderment that the same word, decision, which is

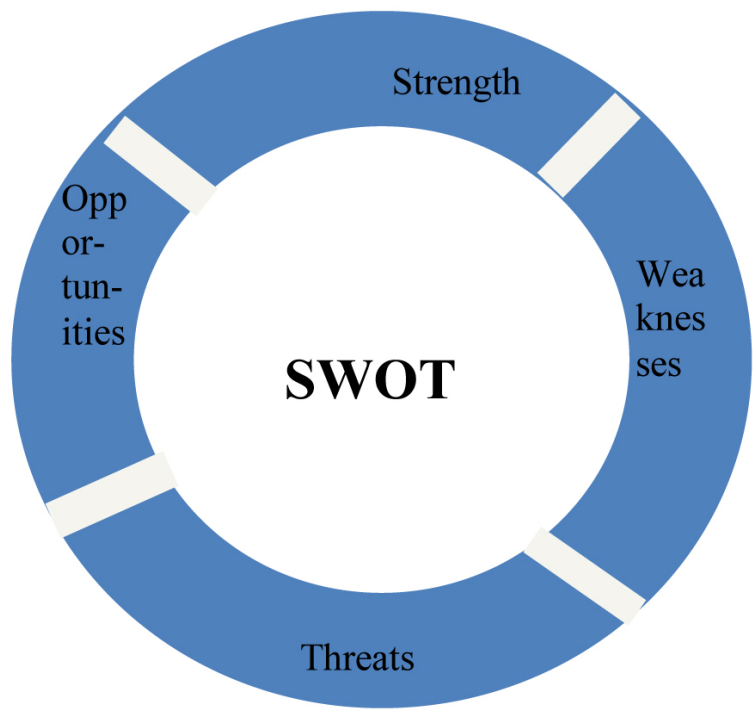

Figure 3. SWOT Analysis. 
used for all of them. The equal term is applied to activities as well as complex deliberations, to both small stakes bets and highs takes commitments, and to exploratory steps as good as irreversible moves as shown in Figure 4. It stands to reason that insights about selections in one kind of circumstance might no longer owning lighter on decisions in one other. Even worse, they'll lead a resolution maker off beam.

This list gives the owner or the managers to be in safer side as much as to minimize the loss or weaknesses and to avoid any future threats [27].

Most common factors of strategies in order to improve any decision making are mentioned as:

1) Difficulties

To avoid any loss and making the solution to be easier also improving the decision making is done by listing all difficulties.

2) Support

For improving the decision making, it is better to have support from friends, relatives and others that is no need to go through decision making lonely.

3) Deep thinking

In this section, deep thinking means that searching for any reason which complicates things.

4) Alternatives

Considering with a wider range by mentioning or explaining to others for best in order to obtain alternatives for the plan.

5) Goal clarification

Required goals in a wider context so that the decision will be easier to take it from the collected alternatives.

6) Real view of consequences

Keeping things in point of view is valuable than overvalue all negative outcomes of any decision.

7) External help

External help may be obtained by psychologist to help in exploring decision making as shown in Figure 5.

\section{Cognitive View of Strategy}

The cognitive technique is any emotional process or even Means of achieving a

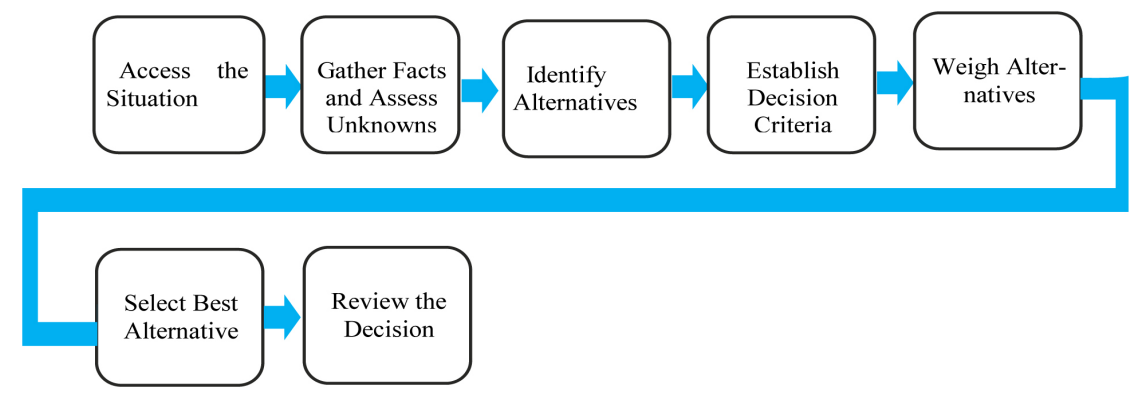

Figure 4. Classic decision making. 


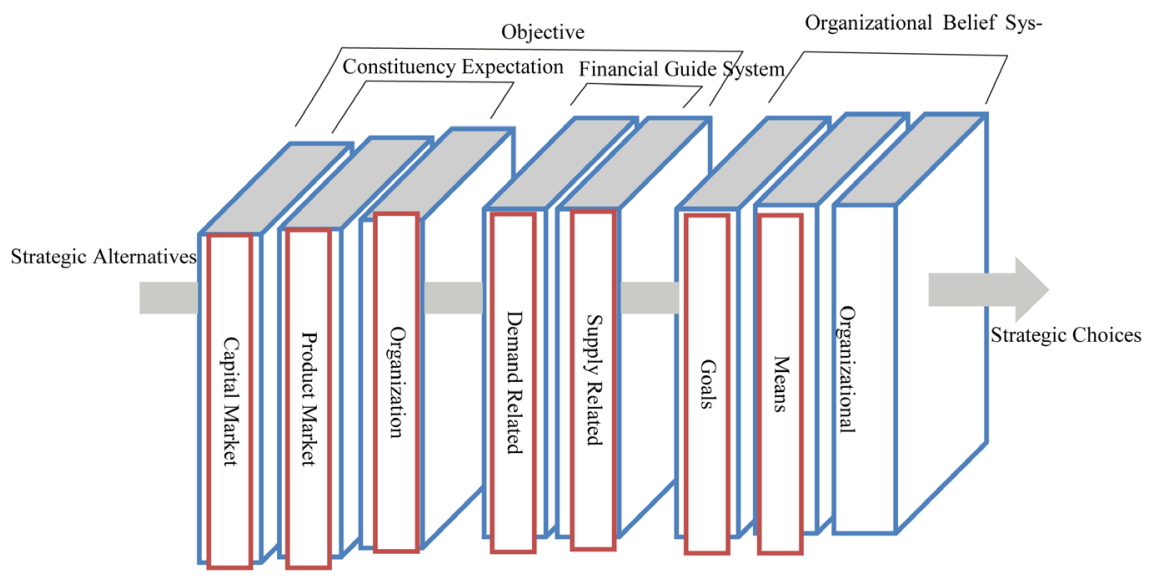

Figure 5. Donaldson-Lorsch Model of Decision-Making.

certain mental aim. The particular mental techniques in which students use impact the way they will perform in class, along with the points they can accomplish outside of school. Researchers have discovered that effective pupils and also thinkers make use of more efficient methods for learning, producing, concern repairing, as well as thought compared to useless pupils and also thinkers because demonstrated inside Figure 6.

\subsection{Rational Techniques}

Rational techniques may be basic or perhaps particular. Basic mental techniques are often strategies that may be utilized all through many different treatments as well as circumstances including summarization or possibly setting up objectives for which to perform, whilst specific mental methods are generally thinner methods which is often provided in the direction of a particular kind of job including drawing a picture to help an individual see how in order to handle a science issue. Particular methods will be more efficient nonetheless work with a more limited array of make use of. Efficient students make use of each basic as well as specific technique; Strategies already are recognized coming from capabilities. Although experience resembles strategies, they may be different because they're accomplished quickly, whilst techniques usually require men and women to take into consideration exactly what method they may be making use of. Successful learners produce the opportunity to utilize methods immediately whilst showing right after people methods at the suitable moment. People who can easily keep in mind their particular cognition as well as mental techniques have been proven to get metacognitive awareness.

An individual element in which determines whether or not students work with a method is actually college students know very well what the process is and also ways to input it to use. Method take advantage of could be afflicted both through understanding of what are the strategy is and methods to place it to utilize, through perception inside the effectiveness from the technique. Just one reason why students might not work with an effective technique is that they 


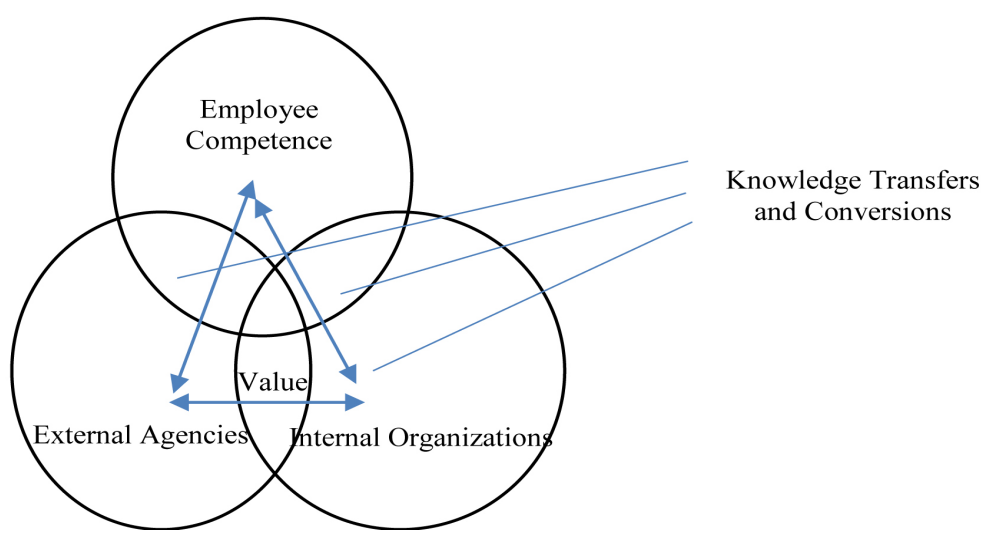

Figure 6. Completing the Knowledge-based View of Strategy Formulation.

have no idea regarding it. For instance, enrollees who examine by simply reading through a novel area one more period of time may not recognize that greater techniques include make an effort to trying to sum up the text and looking to explain difficult suggestions to on their own. An additional reason pupil will not utilize methods is that they may well not think the process is beneficial or even beneficial. Students who's urged to sum up the specific phase may well not accept is as true will truly improve knowing, or the student may perhaps acknowledge that it will enhance understanding but in which the amount of further learning is not worth the moment which usually outlining takes.

\subsection{Knowledge, Strategic Theories of Learning}

The perform regarding successful strategies in learning along with contemplating is really outlined by many tips concerning studying in addition to advancement. Details running advocates manage methods because methods which usually conduct themselves after details in functioning storage space in ways that boost safe-keeping as well as understanding by means of better interconnections together with current info. As an example, elaborating details is an effective approach because it brings together completely new details with data restored coming from long-term memory space.

Constructivists highlight the particular part associated with methods given that students develop clean information. Strategies including finding difficulties with knowing about it can help students produce brand new understandings. College students which usually realize efficiently might have an assortment associated with effective techniques for creating understanding preserved.

Enrollees internalize techniques after first coming across these kinds of inside staff discussions. As an example, pupils may possibly internalize The procedure associated with critiquing their own creating after taking part in collaborative discussions where colleagues evaluation a single another's producing Interpersonal psychological advocates stress The particular operate associated with successful method use in being a self-regulated college student. Self-regulated pupils are generally those people who are good at managing their particular under- 
standing processes without outdoors supervision or perhaps assist. Self-regulated pupils might have arranged objectives regarding understanding, select methods to accomplish such goals, monitor regardless of whether they are usually achieving these kinds of objectives, producing adaptations in the event that objectives aren't obtaining achieved.

\subsection{Cognitive Strategies}

There are numerous lines regarding investigation in which aid the significance of mental methods inside mastering and in addition considering. A single well-known kind of study even arrives near professionals in addition to rookies or perhaps adept university students together with smaller amount proficient college students. Researchers with such strategies are finding substantial variations inside technique use in between countless a reduced amount of skillful students, reasons, and also trouble solvers.

An additional distinct analysis experimentally investigates the results of coaching college students to perfect by employing a technique and even set of strategies. Quite a few these kinds of research have indicated which students which study the fresh techniques outperform those who failed to study the methods.

One third unique research arises from long-term school experiments or perhaps quasi-experiments, Studies generally prior almost a year, normally a complete school 12 months. These folk's distinctions a standard school program that won't focus significantly on technique training in addition to curricula in which educate students several intellectual strategies. This research indicates by using very carefully created instruction, college students' performance about steps associated with knowing, thinking, and/or difficulty correcting raises.

In the end, researchers have in contrast high-performing universities together with low-performing universities to ascertain when these folks fluctuate inside their emphasis on strategy coaching. Several numerous studies have found that higher-performing universities execute actually emphasis more on assisting college students discover successful intellectual methods than lower-performing universities do.

A lot of the research upon emotional strategies provides searched for to spot particular techniques which are often effective concerning several types of obligations. Most of this particular accessibility can look at strategies that are actually efficient inside comprehension, producing, trouble resolving, as well as considering, along with review several effective domain-general processes for general self-regulation.

\section{Future Research and Discussion}

The Work Study of various leading supervision staff characteristics upon global diversification. Found out that specific leading supervision group characteristics are related to worldwide enlargement. Specifically, results suggested in which 
lower average grow older, greater average tenure, increased typical top-notch training, greater average worldwide expertise, and better tenure heterogeneity tend to be connected with worldwide diversification [27].

The study reinforced the value of top administration team make up inside internationalization decisions and also implies more research in this context. Researched the largest professional companies within Turkey extensively reinforced the actual hypotheses produced from this kind of philosophy. During the early stages associated with monetary liberalization the average grows older and typical organizational period of top management teams (TMTs) were associated with the actual export orientation regarding, while in later phases, overall performance grew to become a significant predictor of the staff characteristics. Instructional background qualities regarding teams appeared to be under more robust institutional difficulties, modifying in different methods in the face of macro-level modify.

Explored the relationship between the two most important perspectives of the firm, the resource-based view (RBV) and the knowledge based view (KBV), by examining the relative impact of firm specific assets and knowledge capabilities on the firm's competitive advantage. Moreover, proposed composite models which elaborate up on both perspectives causal logic with respect to the conditions relevant for the firm success [28].

Singh, tested the relationship between knowledge sharing practices within and between trading partners as a framework for integration, and tested for the effect of these practices on firm performance. Structural equation modeling approach to data analysis was used. Moreover, the three knowledge related constructs internal knowledge integration, knowledge integration with customers, knowledge integration with suppliers were strongly inter-related, providing a case for knowledge based integration of firms with their trading partners. Further, these three exogenous constructs collectively explained about a third of the variance in the endogenous construct firm performance. The relationships identified and provided support for the efficacy of knowledge based collaboration.

The partnership between the demography regarding leading supervision teams and also business strategic modify, measured since total alteration of diversity degree, in just a test of lot of money five-hundred organizations. Handling for earlier firm overall performance, organizational dimension, leading group dimension, and also industry framework, found out that the firms probably to undergo alterations in company strategy had leading management groups seen as a lower common grow older, reduced company tuner, increased group tenure, increased instructional stage, higher instructional standards heterogeneity, and higher academic lessons in the science compared to some other teams [29].

Based on justifications coming from leader life routine and also top echelons concept, also conceptualized the formerly fragmented literatures about company/industry dependent, experience centered and also persona dependent process 
information into an integrated concept of process understanding within the head existence period concept. Because of these particular, constant hypotheses around the good impact better task knowledge as well as the tangible impact on the form from the leader existence routine curve are already extracted. Moreover, additional a genuine group features dependent technique to primary psychological persona actions of the professional's intellectual foundation [30].

The determined constraints in which impact this technique, allowing us all to understand more about models of the particular conversation in between ideal as well as Implicit modifications during vasomotor adaptation. When the adaptation phase had been lengthy, participants eventually changed their own process to counteract the rise in endpoint problems. Additionally, taken out visual markers in which provided external landmarks to guide a strategy, the degree regarding move was sharply attenuated. These kinds of effects tend to be included by way of a set-point state-space model when a strategy is flexibly altered to counteract efficiency problems arising from the particular version of an inner product. A lot more typically, these kinds of final results declare that proper procedures might operate in many studies associated with adaptation, with participants arriving at any synergy from a strategic program and the results of sensorimotor version, this assertion may exclude CEOs' prior experiences, since it implicitly assumes that all new CEOs have the same inclination toward change. By viewing a $\mathrm{CEO}$ as an individual embedded within his/her experiences and relationships throughout his/her career, we propose that CEO newness a concept integrating prior board experience, prior heir apparent experience, and length in the current position can provide a more complete assessment of a new CEO's tendency toward change. Moreover, argued that the impact of (CEO) newness on strategic changes will be moderated by the strategic distance between a focal firm and a (CEO's) previous firm, as well as the industry similarity between the two firms.

\section{Conclusion}

\section{Research Conclusions}

In this work, collection of strategy definitions, research methods, industrial economics view of strategy, and the resource theory debate that any company implements better case if it gathers the valuable resources and no-prospective. While, when the company can handle all these resources as a unique strength, then the company will enter a longer period of success. Exceptional varieties of intellectual property incorporate patents, emblems, copyrights, and exchange secrets and techniques.

\section{References}

[1] Khadar and Abu, B.M. (2018) The Impact of Organizational Culture on Employee's Satisfaction at the Jordanian Company of Investments "Safe-Way". American Journal of Industrial and Business Management, 8, 13-26.

https://doi.org/10.4236/ajibm.2018.81002 
[2] Al Qahtani, S.A.M. (2014) Top Management Teams' Influence on Strategic Decision Making and Firms' Outcome in the Case of Saudi Arabia's Private Sector. University of Southampton, Southampton.

[3] Sadeghinejad, Zahra and Najmaei, A. (2013) Top Management Team Entrepreneurial Behavior: Insights from Team Process. 03. Entrepreneurship, Small Business and Family Enterprise Competitive Session.

[4] Barron, J.M., Chulkov, D.V., Waddell, G.R., Barron, J.M., Chulkov, D.V. and Waddell, G.R. (2011) Top Management Team Turnover, CEO Succession Type, and Strategic Change. Journal of Business Research, 64, 904-910. https://doi.org/10.1016/j.jbusres.2010.09.004

[5] Bugental, D.B., Ellerson, P.C., Lin, E.K., Rainey, Kokotovic, B.A., and O’Hara, N. (2002) A Cognitive Approach to Child Abuse Prevention. Journal of Family Psychology, 16, 243-258. https://doi.org/10.1037/0893-3200.16.3.243

[6] Cervone, D., William G. Shadel, W.G., and Jencius, S. (2001) Social-Cognitive Theory of Personality Assessment. Personality and Social Psychology Review, 5, 33-51. https://doi.org/10.1207/S15327957PSPR0501_3

[7] Cohen, J.F., and Dennis, C.M. (2010) Chief Information Officers: An Empirical Study of Competence, Organizational Positioning and Implications for Performance. School of Economic and Business Sciences, University of the Witwatersrand. SAJEMS NS, 13, 203-221. https://doi.org/10.4102/sajems.v13i2.46

[8] Curado, C. (2006) The Knowledge Based-View of The Firm: From Theoretical Origins to Future Implications. ISEG-UniversidadeTécnica de LisboaRua Miguel Lupi, Lisboa, 1-18.

[9] Curado, C., and Bontis, N. (2006) The Knowledge-Based View of the Firm and Its Theoretical Precursor. Inderscience Enterprises Ltd. International Journal of Learning and Intellectual Capital, 3, 367-381. https://doi.org/10.1504/IJLIC.2006.011747

[10] Datta, Sudip, and Iskandar-Datta, M. (2014) Upper-Echelon Executive Human Capitaland Compensation: Generalist vs Specialist Skills. Strategic Management Journal, 35, 1853-1866. https://onlinelibrary.wiley.com/

[11] Masanell, R.C. and Ricart, J.E. (2009) From Strategy to Business Models and to Tactics. Working Paper, Harvard Business School, Boston, 1-45.

[12] Myerson, R.B. (1996) Nash Equilibrium and the History of Economic Theory. Department of Economics, University of Chicago, 1-35.

http://home.uchicago.edu/ rmyerson/

[13] Nickols, F. (2016) Strategy Definitions \& Meanings, 1-14. http://www.nickols.us/articles.html

[14] Seddon, Peter and Lewis, G. (2003) Strategy and Business Models: What's the Difference? PACIS 2003 Proceedings, 17.

[15] Porter, M.E. (1980) Competitive Strategy Techniques for Analyzing Industries and Competitors. The Free Press, A Division of Simon \& Schuster Inc., New York.

[16] Porter, M.E. (1985) Strategy and Competitive Advantage. Competitive Advantage Is at the Heart of a Firm's Performance in Competitive Markets. New York Free Press, New York.

[17] Porter, M.E. (2001) Strategy and the Internet. Harvard Business Review, 79, 62-78.

[18] Pourabdollahian, G. and Copani, G. (2014) Proposal of an Innovative Business Model for Customized Production in Healthcare. Modern Economy, 5, 1147-1160. https://doi.org/10.4236/me.2014.513107 
[19] Seddon, P.B. and Lewis, G.P. (2003) Strategy and Business Models: What's the Difference. Department of Information Systems, The University of Melbourne, Victoria, 236-248.

[20] Sherin, B. and Fuson, K. (2005) Multiplication Strategies and the Appropriation of Computational Resources. Journal for Research in Mathematics Education, 36, 347-395.

[21] Singh, P.J. (2009) Knowledge Based View of Supply Chain Integration. Department of Management \& Marketing, The University of Melbourne, Melbourne.

[22] Brewster and Chris (2017) The Integration of Human Resource Management and Corporate Strategy. Policy and Practice in European Human Resource Management. Routledge, 22-35.

[23] Wiersema, M.F. (2010) Top Management Team Demography and Corporate Strategic Change. Academy of Management Journal, 35, 91-121. https://doi.org/10.2307/256474

[24] Wulf, T., Roleder, K. and Frisch, S. (2011) The Impact of a CEO's Task Knowledge on the Leader Life Cycle. Working Paper Chair of Strategic Management and Organization, HHL Leipzig Graduate School of Management, Leipzig.

[25] Yamak, S. and Usdiken, B. (2006) Economic Liberalization and the Antecedents of Top Management Teams: Evidence from Turkish "Big” Business. British Journal of Management, 17, 177-194. https://doi.org/10.1111/j.1467-8551.2006.00491.x

[26] Abu Khadar, B.M. (2018) The Impact of Organizational Culture on Employee's Satisfaction at the Jordanian Company of Investments "Safeway". American Journal of Industrial and Business Management, 8, 13-26.

[27] Paiva, E.L., Roth, A.V. and Fensterseifer, J.E. (2008) Organizational Knowledge and the Manufacturing Strategy Process: A Resource-Based View Analysis. Journal of Operations Management, 26, 115-132. https://doi.org/10.1016/j.jom.2007.05.003

[28] Kraaijenbrink, J., Spender, J.-C. and Groen, A.J. (2010) The Resource-Based View: A Review and Assessment of Its Critiques. Journal of Management, 36, 349-372. https://doi.org/10.1177/0149206309350775

[29] Zheng, W., Yang, B. and McLean, G.N. (2010) Linking Organizational Culture, Structure, Strategy, and Organizational Effectiveness: Mediating Role of Knowledge Management. Journal of Business Research, 63, 763-771. https://doi.org/10.1016/j.jbusres.2009.06.005

[30] Lu, Y., Tsang, E.W.K. and Peng, M.W. (2008) Knowledge Management and Innovation Strategy in the Asia Pacific: Toward an Institution-Based View. Asia Pacific Journal of Management, 25, 361-374. 